\title{
Estudo de caso sobre a experiência com a "pressão alta"
}

\section{| ${ }^{1}$ Ana Maria Canesqui I}

Resumo: Aborda-se a experiência com a "pressão alta" e enfermidades associadas postas como sofrimentos físicos e morais na totalidade da pessoa que vive, reflete e atua em meio às circunstâncias de vida que a afetam. Trata-se de estudo de caso integrante de uma investigação qualitativa sobre narrativas e significação da "pressão alta", feita com 17 homens e 20 mulheres diagnosticados há mais de um ano com hipertensão arterial, usuários de uma unidade de Saúde da Família de uma cidade interiorana paulista. Dois motivos nortearam a seleção do caso: estar incluído entre os sete indivíduos entrevistados que mencionaram ter descoberto a hipertensão na ocasião em que passaram pelo infarto cardíaco ou pelo derrame cerebral e pertencer ao gênero feminino. As informações foram obtidas mediante entrevistas semiestruturadas sobre as condições percebidas de saúde, a descoberta da enfermidade, as explicações sobre sua gênese, os itinerários terapêuticos, os apoios sociais recebidos; as relações com os serviços de saúde e outros agentes de cura e o gerenciamento das prescrições médicas. Demonstram-se as interconexões da experiência pessoal e singular do adoecimento com os contextos socioculturais mais amplos, com os valores morais, relações sociais e as representações sociais sobre corpo, saúde, doença e cuidado compartilhados com a classe trabalhadora.

> Palavras-chave: experiência com a enfermidade; hipertensão arterial, ciências sociais e saúde; pesquisa qualitativa em saúde.
1 Doutora em Ciências e Livre-Docente em Ciências Sociais Aplicadas à Medicina. Departamento de Saúde Coletiva. Faculdade de Ciências Médicas. Universidade Estadual de Campinas, Brasil. Endereço eletrônico: canesqui@fcm. unicamp.br
Recebido em: 16/04/2013. Aprovado em: 15/09/2013. 


\section{Introdução}

É bastante pertinente abordar a experiência com as enfermidades de longa duração consideradas crônicas pela biomedicina, geralmente invisíveis, multifatoriais, cujas causas nem sempre são conhecidas, e que impõem aos adoecidos prolongado convívio com elas, demandando encontros frequentes com os médicos e profissionais de saúde, sem a eles se restringirem. Essas doenças produzem impactos sobre as vidas dos sujeitos e seu entorno, em função de suas especificidades e transtornos ocasionados. Anselm Strauss foi o primeiro sociólogo a abordar os significados e a experiência com essas enfermidades, afirmando que as "doenças crônicas são de longa duração, incertas, múltiplas, requerem paliativos, porque são incuráveis” (STRAUSS; GLASER, 1975, p. 16).

A hipertensão arterial sistêmica, clinicamente apresentada como assintomática, crônica, multifatorial, de risco para outras enfermidades (cardiovasculares, complicaçōes renais, cerebrovasculares e outras lesōes) é incurável, porém controlável pelas tecnologias médicas. É crescente problema de saúde pública e seu controle, vigilância e monitoramento são objeto da política nacional de saúde. Sua prevalência abrange $35 \%$ da população jovem e adulta acima de 40 anos (BRASIL, 2006).

Nas análises sociológicas das enfermidades crônicas, destacam-se no contexto anglo-saxão as abordagens da experiência da enfermidade revistas por Pierret (2003). A autora aponta uma fase inicial das pesquisas centrada na experiência subjetiva, abordando as metáforas, representações cognitivas, imagens e aprendizagem em relação ao adoecimento, formas de enfretamento e os manejos para amenizar seus efeitos. Os estudos também incluíram nesta fase o estigma, a vergonha e a perda do "eu" em torno de algumas enfermidades e análises das narrativas. Outra fase das investigações centrou-se nas interações dos pacientes com os demais, incluindo a organização familiar e as atividades ocupacionais; as diferenças de gênero, étnicas e sociais; as ações de "coping", estilo e normalização, ${ }^{1}$ integrantes das modalidades ou estratégias de ajustamento à enfermidade, apontando-se mais recentemente a necessidade de relacionar a experiência pessoal e subjetiva com os contextos políticos, econômicos e socioculturais mais amplos.

Compartilha Pierret das sugestôes do sociólogo inglês Michel Bury (1991, p. 453), sobre a necessidade de as pesquisas relacionarem as experiências singulares e os significados com a organização do cuidado médico, a interferência da mídia, 
das associações e movimentos de pacientes e com o consumismo, a que esse autor

designa de "externalidades" contextuais à experiência, enquanto Pierret prefere reportá-los genericamente à "estrutura social" 2 (2003, p. 8). Sugere a autora que esse tipo de análise deve ultrapassar a análise dos fatores sociais e econômicos para incluir os efeitos dos pertencimentos de classe social, gênero, etnia, idade e as influências do contexto geral na experiência da enfermidade, assim como os efeitos sobre a organização do cuidado, das instituiçōes e no saber médico, sempre mutáveis no tempo e na história das sociedades.

Pierret admite a raridade de estudos anglo-saxões nesta direção, que aderem às perspectivas sincrônicas e anistóricas. Entretanto, menciona algumas investigaçôes britânicas como exemplares da ultrapassagem da experiência subjetiva e individualizante da enfermidade, enfocando os impactos do contexto socioeconômico e das ideologias sociais mais amplas na construção de certos eventos vitais (menopausa e envelhecimento) e doenças; o papel da política de saúde, do sistema de cuidado, do conhecimento médico e dos modelos e imagens corporais difundidos pela mídia sobre a experiência com a enfermidade. Acrescenta a necessidade de os estudos abordarem a relação entre a biologia, as emoções e o corpo na experiência da enfermidade e incapacidade.

A sociologia está mais presente do que a antropologia nas investigações anglosaxônicas sobre a experiência com as enfermidades de longa duração. Entretanto, a antropologia médica norte-americana aproximou-se do paciente, afirmando ser a doença profundamente individual por alcançar o mundo subjetivo, corporal e íntimo, inscrevendo-se nas biografias dos sujeitos e nos contextos cultural e moral (KLEINMAN; SEEMAN, 2000), sempre localizados nos tempos e nos espaços sociais historicamente construídos, transcendentes ao mundo prático e imediato. Uma parte desta literatura abordou a relação da experiência pessoal com o sofrimento e os construtos socioculturais, morais e relacionais sem se ater tão somente à dimensão pessoal/subjetiva e orgânica.

É relativamente escassa a produção acadêmica nacional sobre a hipertensão do ponto de vista da investigação qualitativa em interlocução com as ciências sociais e humanas. Uma revisão a respeito nas bases eletrônicas de informações científicas como Lilacs e Biblioteca Virtual de Saúde Pública identificou 146 artigos, teses de doutorado e dissertações de mestrado na palavra-chave hipertensão (CANESQUI, 2007). Distribuiu-se esta produção científica, segundo os tipos 
de estudo, em: epidemiológicos (40\%); serviços médicos-assistenciais (17,0\%); clínicos, experimentais e farmacológicos (13,0\%); adesão/não adesão aos tratamentos médicos $(2,5 \%)$; psicologia e cognição $(2,5 \%)$; ciências sociais e humanas (8,0\%); outros (17,0\%). Incluíram-se nesta última categoria os estudos reportados à palavra-chave hipertensão, sem abordá-la exclusivamente.

As investigações relacionadas às ciências sociais e humanas, geralmente feitas entre mulheres pertencentes às classes trabalhadoras de baixa renda, aproximaramse mais raramente da análise da política de saúde dirigida à hipertensão, mas principalmente da pesquisa antropológica, enfocando o modelo de signos, significados e ações; a análise de narrativas; as representações da enfermidade; a identidade e localidade, perpassando os discursos sobre a enfermidade e as relações com os tratamentos médicos. Os estudos se deram a partir do final da década de 1980 em diferentes contextos urbanos e regiōes do país, sendo seus autores cientistas sociais ou profissionais de saúde. Não se registraram nesta revisão da literatura pesquisas sobre a experiência com a "pressão alta".

Investigaçôes sobre o uso de serviços de saúde em áreas cobertas pela Estratégia de Saúde da Família (ESF) no município de São Paulo apontam certo nível de acesso e uso dos serviços de saúde na população residente em áreas empobrecidas daquele município, mesmo que não cobertas pela ESF (GOLDBAUM et al., 2005). Admitem os autores que esta estratégia foi capaz de reduzir os efeitos das condiçôes sociais desiguais, medidas através de variáveis socioeconômicas e demográficas selecionadas sobre o perfil do acesso e de uso dos serviços de saúde com melhora da equidade social. Acrescentam também que, uma vez efetivamente implantada, esta estratégia produz impactos no perfil do acesso e uso dos serviços de saúde (GOLDBAUM et al., 2005).

Voltando a atenção a uma parcela de hipertensos usuários de uma unidade da ESF da cidade de Amparo, Estado de São Paulo, não se investigou localmente a implementação desta estratégia, vigente há 11 anos na cidade no momento de realização da pesquisa que deu origem ao estudo de caso abordado neste texto. Entretanto, avaliações e pesquisas sobre os vários aspectos daquela estratégia apontam os obstáculos e efetiva implementação no território nacional, em especial a desejada mudança do modelo assistencial, admitindo possibilidades de superação dos problemas encontrados (CAMARGO JR., 2008). Apontam também as avaliações empreendidas diferenças na cobertura populacional, a importância no 
acesso das populações empobrecidas à atenção básica, os problemas relacionados

ao financiamento, a implementação parcial de algumas atividades previstas, além de outros aspectos (BRASIL/MS, 2002a; 2002b; 2005).

Esse tipo de atenção básica procura submeter os pacientes às normas médicas no controle da hipertensão arterial e na prevenção de seus riscos. Apesar disto, é importante abordar a complexidade da experiência com a enfermidade. Trata-se de um processo atravessado por múltiplas dimensões: situacionais, sociais, morais, afetivas, relacionais sempre permeando os contextos das vidas dos sujeitos, de seu entorno e grupo social, vivendo sob determinadas condições sociais e de saúde, de classe e gênero.

Este trabalho se centra na experiência com a "pressão alta" e outras doenças coadjuvantes e consequentes, ancorado em um estudo de caso, integrante de uma pesquisa socioantropológica e qualitativa sobre narrativas e significados da “pressão alta” realizada em 2009, entre 17 homens e 20 mulheres diagnosticados com hipertensão arterial há menos de um ano, segundo informaçôes do Cadastro Hiperdia de uma Unidade de Saúde da Família (CANESQUI, 2010). ${ }^{3}$

Os informantes desta pesquisa eram de baixa renda e pertencentes aos segmentos da classe trabalhadora urbana, descobertos pelos planos de saúde privados e primordialmente dependentes dos serviços públicos e filantrópicos de saúde. Residiam nos diferentes setores territoriais de uma área coberta por aquela unidade. Sem abrir mão da interpretação da pesquisadora, enfoca-se o relato na primeira pessoa de uma mulher diagnosticada com hipertensão arterial sistêmica.

\section{Seleção do caso, procedimentos e instrumentos da investigação}

A ESF, dirigida às famílias empobrecidas da cidade de Amparo, permite aos hipertensos cadastrados na unidade de saúde acessar periodicamente a atenção clínica, obter medicamentos e ser acompanhados por uma equipe multiprofissional, atuante na própria unidade e nos domicílios. Nestes últimos dão-se principalmente a visitação e os aconselhamentos médicos e terapêuticos pelos agentes comunitários de saúde aos adoecidos cadastrados.

As informações para o estudo de caso procederam de três entrevistas feitas mediante roteiro semiestruturado. Elas foram gravadas, transcritas e analisadas. Extraiu-se o caso do universo de 37 entrevistados do mencionado 
estudo, selecionando-o por dois motivos: encontrar-se entre os sete indivíduos entrevistados que mencionaram ter passado pela experiência de infarto cardíaco ou de derrame cerebral, como momentos primordiais de descoberta da hipertensão arterial e pertencer ao gênero feminino.

Esse tipo de estudo qualitativo é circunscrito e não pretende generalizar seus resultados. Dá-se sempre em torno de uma unidade (pessoa, instituição, classe de crianças, grupo, comunidade, entre outros). O estudo de caso, segundo Stake (2000), é microscópio, localizado, particular e organizado em torno de um pequeno número de questóes, comportando sempre um recorte. Para o autor, "o

propósito do relato de caso não é representar o mundo, mas representar o caso" (STAKE, 2000, p. 448). Sua análise transcende a experiência pessoal/subjetiva, permitindo dialogar com o contexto mais amplo onde se insere.

A técnica de relato oral foi utilizada, sem conferir total autonomia ao entrevistado à medida que os temas são sugeridos e controlados pelo pesquisador (QUEIROZ, 1987). Os relatos orais são sempre versões da experiência com o adoecimento e os eventos que a cercam. Eles foram fornecidos pela entrevistada à pesquisadora e por ela interpretados. Vislumbra-se, portanto, uma análise do ponto de vista socioantropológico em torno da experiência com o adoecimento e os sofrimentos físicos e morais.

A exposição do caso, através da leitura da experiência com a enfermidade, ultrapassa a doença como fato biologicamente informado, inserindo-a no contexto sociocultural, econômico, moral, relacional e biográfico de quem age, reflete e atua diante dos eventos, não destituído das capacidades reflexiva, interpretativa e da ação. Este estudo de caso é pontual nos aspectos da experiência da enfermidade considerados, tais como: as interpretações das condiçôes de saúde no momento da entrevista; o uso dos conhecimentos eruditos e não eruditos (do próprio grupo social); as explicações à gênese da enfermidade; representaçôes e significações da enfermidade e da condição de adoecimento; a mobilização de recursos de cura (itinerários terapêuticos), os apoios sociais recebidos; a descoberta da "pressão alta”; as formas de controlá-la e de interpretá-la.

\section{Luciana}

Luciana (nome fictício) nasceu em Amparo, onde reside há 58 anos. Casada, mora em casa própria com o marido e uma filha. Os demais filhos casados residem 
em outras cidades. Cursou o ensino fundamental e trabalhou como faxineira

diarista durante algum tempo. Dedicava-se, no momento das entrevistas, apenas aos afazeres domésticos não remunerados, apresentando-se como "do lar". A renda familiar soma três salários mínimos e meio, advindos da aposentadoria do marido e de alguns serviços feitos por ele como “bicos” remunerados.

Apesar de hipertensa diagnosticada, omitiu esta enfermidade quando discorreu sobre seu estado de saúde atual, enfatizando os problemas cardíacos, as dores (no peito e na coluna) e os problemas vaginais, atribuídos ao clima frio, que segundo o senso comum, é responsável pelos desequilíbrios da temperatura ambiental com o corpo quente, impedindo-a sentir-se sadia. Submeteu-se à cirurgia cardíaca há dez anos. Relembra este evento marcante em sua vida, que lhe alterou as rotinas diárias, a própria vida, as condições percebidas de saúde, a capacidade de trabalhar como faxineira e a identidade social de pessoa considerada anteriormente sadia. Nas palavras de Luciana:

Eu não ia ao médico, eu estava com a saúde perfeita, saúde boa. Eu trabalhava, eu cuidava de tudo, fazia de tudo. Aí aconteceu aquele sangramento. Fui correndo para o hospital. Passaram algumas horas e o médico mandou voltar para a casa e procurar um cardiologista. Fiz cateterismo, a enfermeira me levou para São Paulo e melhorei um pouco. Mas não teve jeito. Passei por muitos exames, fiz duas angioplastias, exames de sangue, exame do coração. Sofri bastante. Não teve jeito. Operei o coração. Voltei a casa e estava bem, mas eram muitos problemas na família [...]. Depois faleceu meu filho, há três anos. Eu sofro muito. Sinto falta dele, mas minha tristeza é porque quem morava com ele não cuidava dele e eu não podia cuidar. Sabe o que é pensar no filho desde a hora que levanta até quando vai dormir?Tomo remédio, levanto, penso de novo nele o dia inteiro. Não me esqueço dele... e aí fiquei pior porque aumentaram as dores.

A centralidade no relato de Luciana das dores, dos eventos relacionados ao coração e às perdas (da saúde e do filho) traduz sofrimentos físicos e morais. Ao lado disso, o coração condensa simbolismo socialmente compartilhado como órgão sede da vida e das emoçôes, compreendendo as significaçôes e a importância da cirurgia neste órgão nas suas explicações e os efeitos simbólicos e concretos sobre seu corpo e pessoa.

Além do sangramento, simbolizando perigo de vida e necessidade urgente de atendimento médico, ela relata detalhadamente o atendimento obtido no hospital por ocasião da cirurgia cardíaca. Exceto a cirurgia, os demais atos médicos aos quais se submeteu por ocasiāo da internação hospitalar não foram inteiramente inteligíveis. Refere-se às frequentes manipulações de seu corpo nos 
atos de examinar, de controlar os sinais vitais feitos por médicos e enfermeiros, aos vários exames laboratoriais e por imagem aos quais se submeteu, a administração frequente de medicamentos nos horários previstos e a maior concentração naquele espaço de profissionais, especialistas e tecnologias médicas.

Este conjunto de atos médicos e o uso de tecnologias mais sofisticadas forneceram à Luciana certeza de ter sido examinada exaustivamente, solucionando temporariamente os problemas e as dores no peito. O hospital, nas representações do senso comum, é lugar onde se dispõe de "bom atendimento", ou seja, do acesso às tecnologias médicas, aos médicos especialistas e aos exames sofisticados (CANESQUI, 1992), todos indisponíveis na atenção básica. É também espaço pouco familiar às pessoas das classes trabalhadoras.

No tempo decorrido após a cirurgia, Luciana reitera seus esforços permanentes e contínuos de procurar os serviços de saúde, da frequente relação com os médicos para resolução dos males físicos e morais que a afligem, vendo-se transformada de pessoa "forte" (disposta para o trabalho e resistente, segundo o senso comum) em pessoa "nervosa", fragilizada física e moralmente. Relata: "faz dez anos, não fiquei bem mais. Passa uma semana, semana passa e eu faço as coisas e você pode ver. Não são como eram antes."

A ruptura biográfica, na expressão de Bury (1982), inclui a experiência com as condições crônicas na qual a estrutura da vida cotidiana, seus significados e formas de conhecimento são interrompidos, levando o adoecido a questionar o sentido de sua existência, a autoimagem e as explicaçóes do adoecimento e de sua condição. Este processo não estanque comporta a reorganização biográfica contínua no desenrolar do tipo de enfermidade, das circunstâncias de vida e de seu entorno e, provavelmente, no contato com as intervenções médicas regulares.

Os itinerários terapêuticos percorridos por Luciana incluem, além da medicina, dos médicos e serviços de saúde, os agentes religiosos e o uso de recursos informais de cura. Este conceito se refere à busca de cuidados, às ações, interpretações e significação não submetidas a um único padrão. Massé (1984) lembra as múltiplas variáveis (situacionais, sociais, psicológicas, econômicas, ideológicas e culturais) envoltas na procura e busca de cuidados médicos também circunscritos, tanto pela ideologia e valores, quanto pelo perfil do acesso e disponibilidade de tecnologias. 
No caso da hipertensão arterial, os itinerários terapêuticos investigados apontam a valorização do sistema formal de saúde e do saber médico especializado (TRAD et al., 2010) sem que o processo interpretativo seja estático e inicialmente apreendido em um dado momento das vidas dos adoecidos. Luciana circula entre os vários serviços públicos ou filantrópicos de saúde ofertados na cidade sem encontrar solução para as queixas, sofrimentos e obtenção do exame de raios X, considerado indispensável. Nas suas palavras:

Fui três vezes, três semanas em seguida ao Grêmio (serviço médico do Sindicato). Fui lá porque não aguento ir ao postinho de manhã. Eu não aguento ir cedo. Fui ao Grêmio, tomei injeção que tira a dor. Aí o médico passou Dipirona com Benzetacil. Tomei, mas a dor voltou após alguns dias. Fui lá de novo. Aí o médico falou: não precisa vir mais, não precisa voltar aqui para fazer exame mais minucioso para ver esta dor nas costas porque a dor no peito já foi operada. Eu não voltei. Vou voltar lá dia trinta. Vou passar com a enfermeira. Aí eu tenho que tirar radiografia, tem que pedir. Eu acho que tenho que tirá-la com urgência.

As dores não cessam na interpretação do sofrimento de Luciana. Ela insiste em encontrar solução junto aos médicos e serviços de saúde. Dirigiu-se a um pronto-socorro na expectativa de obter o pedido de raios X. Diante da nova recusa do médico, justificada, por ela, pelo fato de não apresentar dor na coluna no dia da consulta, não desistiu. Planejava retornar à unidade de Saúde da Família para solicitar aquele exame. A relação com os médicos, os serviços e profissionais de saúde, com seus saberes, informações e intervenções também compõem o universo da experiência com o adoecimento, seja para legitimar, demandar ou recusar as intervenções médicas.

De um lado, a experiência do sofrimento físico e moral de Luciana expresso nas queixas frequentes e insolúveis das dores são deslegitimadas pela biomedicina, empurrando-a para o "limbo diagnóstico" (CORBIN; STRAUSS, 1985) ou na "incerteza existencial” (ADAMSON, 1977). Além disso, observase nas investigações feitas com pacientes cardíacos atendidos em uma unidade de pronto-atendimento na cidade de São Paulo que, aos classificados como "poliqueixosos" (CHAMMÉ, 2000) pelos profissionais de saúde, imputam-se "dores imaginárias" ou "psicológicas" e a busca frequente dos vários serviços de saúde. Ele observa que esse tipo de "paciente":

[...] constantemente envolto em processos por ele próprio denominado de "procura pela cura" rotinizando ações, perfazendo trajetórias, ritualizando costumes, ilustran- 
do situações, descrevendo o próprio corpo adoecido segundo as instâncias de seu imaginário alimentado pelas condições inumeráveis de convivência com as doenças. Procurando fazer-se compreender espera, em vão pela atenção médica e consequente diagnóstico favorável aos seus desejos de ser, ao mesmo tempo, ouvido, seduzido e amado (CHAMMÉ, 2000, p. 277).

Não dispomos de informaçôes se Luciana foi categorizada “poliqueixosa” pelos profissionais de saúde. Mas sabe-se pelo seu relato que, apesar de ser hipertensa diagnosticada e de ter passado por problemas cardíacos, suas queixas e insistentes dores expressando o sofrimento físico e moral são pouco ouvidas pelos médicos. A presença de dores expressa a condição de adoecimento, segundo os parâmetros de Luciana e do seu grupo social. Não é casual que ela se queixe, demande remédios e raios X insistentemente. Tesser (2010, p. 64) observa que: "através do "contato exotérico", a metamorfose de sentido dá-se sob maior simplificação e maior grau de "anomias vivenciais" nas interpretações e tratamentos médicos dos adoecidos".

Além dos serviços de saúde acionados, Luciana, contrariando a opinião do marido, retornou após a cirurgia à religião católica em busca de proteção e de amparo divinos, que acredita serem eficazes para "acalmá-la” e minimizar os sofrimentos. Orações, as palavras do padre e a frequência ao ritual católico (missa aos domingos) possibilitam manejar e amenizar a experiência com os sofrimentos físicos e morais que a acometem. As observações de Loyola (1984) sobre os agentes religiosos católicos enquanto recursos de cura são pertinentes:

[...] as religiōes onde a separação matéria e espírito, corpo e alma, é maior, os agentes religiosos (padre, religiosas, pastores) tendem a se limitar à cura da alma, o papel que exercem no domínio do corpo, consistindo apenas em reforçar o ato médico; onde a autonomia do corpo é menor, o espiritual acaba por encontrar a própria autonomia, a matéria a submeter-se ao espírito. (LOYOLA, 1984, p. 18).

Além de obter o apoio do marido e de uma filha, sempre premidos pelas obrigações e deveres familiares e pelo próprio valor da família para as classes trabalhadoras, Luciana recorre a uma amiga que ouve seus lamentos, dores e queixas, ao contrário dos profissionais de saúde que se recusam a ouvi-la. $\mathrm{O}$ apoio da amiga ancora-se na solidariedade e "ajuda", como valor moral das classes trabalhadoras, permeando as relaçôes sociais. Referindo-se a esta amiga, Luciana relata:

Eu tenho uma amiga desde que eu fiquei doente ela nunca me deixou. É amigona mesmo. Ela conversa, às vezes estou aborrecida eu vou lá. Eu descarrego tudo nela: converso, conto e choro. Olha, mas não foi fácil estes três anos. Não foi fácil e 
nunca será. O Dr. X fala para mim: cuide-se mais. A senhora é nova. Não sei o quê

a senhora tem. A senhora precisa deixar de usar roupa preta. Mas, eu não consigo.

Eu sou assim e vai ser assim...

Luciana persiste no luto simbolicamente expresso no uso de roupa preta, publicamente anunciado e comunicado, insistindo junto aos médicos a obtenção do exame de raios X, sem êxito. Acredita na eficácia deste tipo de exame para diagnosticar as dores permanentes na coluna e no peito, que a afligem. À similaridade dos demais componentes de sua classe social, deposita na medicina, nos médicos, nos exames e nos remédios esperanças de resolução do estado de perturbação física e moral em que se encontra.

Vale observar a magia exercida nas representaçôes e demandas do senso comum dos exames de raios $\mathrm{X}$ e de sangue, assim como das cirurgias (representadas como extrativas do mal) fortemente valorizados, não apenas pela extensão do acesso aos processos de diagnóstico e terapêutico, mas pelo fato de responderem à lógica da concretude e não da abstração posta por LéviStrauss (1970) em relação ao pensamento selvagem. Aquele exame permite ao médico visualizar as imagens do interior do corpo e, segundo as representações de Luciana, compartilhadas com seu grupo social, também poderá fornecerlhe visualização e concretude às inexplicáveis, recorrentes e persistentes dores na coluna e no peito, associadas por ela à cirurgia cardíaca e à perda do filho, mobilizando seus lamentos e sofrimentos físicos e morais.

Luciana relata não conversar com outras pessoas sobre a "pressão alta", exceto com a amiga, que a atribui ao "nervoso", explicação que também endossa. Acredita que o "nervoso" deve ser evitado pelo esquecimento das afliçōes, pela ingestão de calmante, pela prática de relaxamento e feitura de trabalhos manuais (confecção de panos de prato). Acrescenta ao relato do próprio estado de saúde o suor que lhe escorre pelo pescoço, pressupondo-o gerado pela falta de hormônios, ressentindo-se do fato de o médico não receitar remédios para aliviá-lo. O suor desperta vergonha e incômodo, acompanhando-a em todos os lugares. Deteriora e macula publicamente a autoimagem de pessoa asseada e limpa, cuja visibilidade quer evitar. Lembra-se que asseio e limpeza são socialmente valorizados em relação à imagem da mulher pertencente aos grupos sociais trabalhadores.

A extensão das categorias higiene e limpeza também se aplica à casa, à comida e aos objetos domésticos, sempre sob os cuidados e obrigações das esposas e mães 
de família (CANESQUI, 2005). Ao lado do suor, Luciana se autorrepresenta "atacada de tudo", de depressão, de obesidade, dos problemas de tireoide, sempre aludidos ao tempo decorrido após a perda do filho e a cirurgia, como expressões dos sofrimentos físicos e moral que a afligem.

\section{A descoberta da "pressão alta" e as explicações sobre sua gênese}

Luciana detalhou a descoberta da "pressão alta" respondendo à interrogação da pesquisadora. Associou-a aos sinais corporais de sangramento, quando acometida de infarto, simbolizando perigo de vida, gravidade e necessidade de busca imediata dos serviços médicos. Ela hesitou associar os eventos cardíacos às consequências da hipertensão arterial, postos pelo saber biomédico. Mencionou ter sido diagnosticada anteriormente de hipertensão, somente em outro momento da entrevista. Discorreu detalhadamente o sangramento, a cirurgia, o atendimento hospitalar e a busca contínua dos serviços de cura.

Como eu descobri a pressão alta? Porque uma vez eu estava dormindo, eu acordei cedo quando saiu sangue pelo nariz. Começou a sair sangue pelo nariz, pela boca, todo coalhado; coisa que eu sujei toda a cama. Não vencia toalha de banho. Não vencia toalha de rosto. Então meu marido me levou correndo para o hospital. No hospital falei para o médico: olha como estou. Ele falou: dê graças a Deus que está saindo sangue pela boca e pelo nariz. Sabe, saiu sangue até pelo ânus. Aí ele falou: se tivesse saído pelo olho e ouvido você teria morrido. Aí ele me encaminhou ao Dr. X e comecei a fazer tratamento aos 45 anos. Eu fiz tratamento, não adiantou. $\mathrm{O}$ meu coração não estava aguentando mais. Aí ele me mandou para São Paulo. Operei o coração.

Luciana interpretou que após a cirurgia do coração, a "pressão alta" também pudesse estar curada, tal como a extração do mal por esta técnica médica, dispensando a ingestão de remédio prescrito para ser "tomado para toda a vida". Revelou ter sido anteriormente diagnosticada como "hipertensa" (denominação da doença usada tanto pelos profissionais de saúde quanto pelos adoecidos), afirmando que:

Olha, eu tinha 31 anos e fui ao médico. Ele falou que eu estava com pressão alta, mas eu não liguei. Eu achei que não era; eu era nova ainda. Eu não tomei remédio. Daí veio aquele problema, saiu sangue [...]. Eu achei que não era, continuei comendo o que tinha que comer, aí veio este problema. Eu fui ao médico que cuida de mim até agora, quando eu vim de São Paulo. Não deixei de ir. Ele sabe tudo. Sabe? 
Uma das explicações do senso comum sobre a gênese da "pressão alta", compartilhada com o grupo social, associa-se ao envelhecimento visto como processo natural. $\mathrm{O}$ fato de Luciana considerar-se jovem e sadia, quando fora diagnosticada de hipertensão pela primeira vez, provavelmente interferiu no descrédito do diagnóstico e na recusa de tomar os medicamentos prescritos na ocasião.

É insuficiente a comunicação do diagnóstico médico para que o adoecido reconheça e assuma a condição de adoecimento. Este é um processo envolto nas circunstâncias da vida, nas representações de saúde/doença, nas condições corporais percebidas, na identidade e na própria biografia da pessoa. É frequente o desconhecimento da hipertensão pelos adoecidos, segundo atestam as várias pesquisas populacionais quantitativas feitas localmente ou nas diferentes regiôes brasileiras.

Não é incomum homens e mulheres das classes trabalhadoras ignorarem e desconfiarem do diagnóstico da hipertensão arterial sistêmica, especialmente quando não contam com as sensações corporais. Geralmente desconhecem esta enfermidade e suas consequências, deixando de tratá-la e de controlá-la pelo uso de remédios e de outras medidas preventivas de seus futuros e agravantes efeitos, dentre eles os problemas cardiovasculares e o derrame cerebral, sempre advertidos pelos médicos.

Boltanski (1979) referiu que as classes populares francesas subordinam o uso do corpo às funções sociais, manifestando a doença brutalmente porque não percebem os sinais precursores ou porque se recusam a percebê-los; a doença é vista como acidente imprevisível. A ausência das sensações corporais percebidas, quando fora diagnosticada de hipertensão, também explica em parte o descrédito de Luciana no diagnóstico médico.

Pode-se, entretanto, estender esta explicação corporal a outros domínios, como sugere Barsaglini (2011, p. 149) reportando-se à "interpretação da experiência em determinado ponto ou circunstâncias de vida” - atrelando-se, portanto a descoberta da enfermidade não somente à informação do diagnóstico médico ao paciente. Luciana, quando fora diagnosticada como portadora de hipertensão arterial sistêmica, não se convencera. Julgou-se jovem e ativa para estar acometida da enfermidade. Reportou-se à história da hipertensão na família, envolvendo seus genitores, uma de suas filhas e o marido, sem associar esta condição à 
hereditariedade, como o fazem os médicos, reiterando a importância do "nervoso" e dos comportamentos alimentares na gênese da enfermidade.

Observam-se nas representaçôes sociais das classes trabalhadoras sobre o "nervoso" as múltiplas configuraçôes dos signos associados, isto é: os relacionais, de violência, isolamento, agitação, alterações no discurso, problemas no campo da percepção (delírio e alucinação), ataques e crise, desempenho de papéis sociais, aparência e comportamentos bizarros (RABELO; ALVES; SOUZA, 1999, p. 45).

Esse conjunto de signos se associa às concepçôes de "loucura" abordada por aqueles autores, enquanto Luciana ao referir-se como "pessoa nervosa" reportase ao conjunto das afliçôes de vida que a acometem, materializadas fisicamente nos problemas do coração, nas dores sentidas e em outras queixas, associadas simbolicamente à perda do filho e ao estado geral de sofrimento. Duarte (1986) também lembra as inúmeras perturbações físicas e morais em torno do código do "nervoso" nas classes trabalhadoras, expressando os embaraços da prática da vida.

Revendo as pesquisas qualitativas nacionais de hipertensão feitas entre mulheres das classes empobrecidas (CANESQUI, 2007), nelas figuram explicaçōes da gênese da "pressão alta", os signos relacionais, as emoções contidas, os conflitos e as preocupações domésticas e familiares (MACIEL, 1988; FIRMO; COSTALIMA; UCHOA, 2004; CARVALHO et al.,1998; VIEIRA, 2004).

Pode-se condensar que esta gênese se reporta simbolicamente aos acúmulos dos excessos (sangue, emoções, preocupações, "nervoso", conflitos e dificuldades familiares) que necessitam sair, cuja contenção gera explosôes em partes do corpo. As mulheres das classes trabalhadoras geralmente as contêm em virtude da preservação moral da família, mantendo-se em silêncio. Entre mulheres negras de New Orleans (HEURTIN-ROBERTS; RUSIN, 1983), o temperamento e as emoções estavam entre as explicações das causas da hipertensão, um idioma expressando a interação entre a pessoa e o ambiente social.

Luciana também reitera a importância da alimentação na gênese da "pressão alta" dialogando com as informações médicas aprendidas no controle não medicamentoso da doença, de restringir a ingestão de comidas gordurosas, de sal e de bebidas alcoólicas. Ela reproduz os julgamentos dos profissionais de saúde sobre estes hábitos, que consideram "errados" e postos como responsabilidade moral dos sujeitos, representando a doença como sanção moral à conduta desviante. Essas 
explicações também são compartilhadas com o grupo social de pertencimento de Luciana, aplicando-se à gênese da "pressão alta" e de outras enfermidades.

Entretanto, as explicações de homens e mulheres sobre a gênese da hipertensão do grupo de pertencimento de Luciana foram mais amplas, incluindo, além dos conflitos e dificuldades familiares e no trabalho, o "nervoso e o tipo de alimentação, a hereditariedade, as causas externas (clima e o tipo de vida na cidade) juntamente com o envelhecimento/menopausa" (CANESQUI, 2010, p. 34). Luciana não dispensa tais referências, mobilizando-as segundo interpreta a condição própria do adoecimento e do sofrimento, sempre somada às circunstâncias de vida e à sua biografia.

O senso comum reproduz expressões da linguagem usada pelos médicos nas comunicações com a clientela, referindo-se à "pressão alta" como doença "traiçoeira", "silenciosa", "grave", "imprevisível" e "incurável". Para o senso comum, ela se explica basicamente pela movimentação e qualidade do sangue e dos nervos (CANESQUI, 2010).

\section{A relação de Luciana com os tratamentos médicos prescritos}

O controle da hipertensão arterial pelo saber médico inclui o uso regular de medicamentos, a prática de atividades físicas, a verificação regular da pressão arterial, o acompanhamento médico periódico e a restrição do consumo de alguns alimentos, tabaco e bebidas alcoólicas. Os médicos e as agentes de saúde da ESF recomendam mudar o estilo de vida, combater o sedentarismo, alterar os hábitos alimentares, tomar remédio diariamente e submeter-se aos controles e acompanhamento médico regularmente. Luciana não dispensa inteiramente esses aconselhamentos, gerenciando-os segundo suas interpretaçôes, experiências corporais, conhecimentos de senso comum e conveniências da vida diária.

Ela relata ingerir medicamentos para controlar a "pressão alta", regulando seu uso segundo interpreta e observa as sensaçōes corporais. Acessa os antihipertensivos gratuitamente na unidade de Saúde da Família, cuja disponibilidade é irregular, segundo opera a política governamental de doação de medicamentos às populações de baixa renda portadoras de hipertensão arterial sistêmica. Acredita que tanto os remédios, quanto as restrições alimentares, ao lado do autocontrole 
do "nervosismo", do descanso e do lazer favorecem equilibrar a "pressão alta", cuja cura significa libertar-se do consumo de remédios e da restrição alimentar. Em contrapartida, a dependência dos remédios e a necessidade de adotar dietas específicas associam-se à representação de estar doente, cuja superação não dispensa a fé em Deus, nos médicos e na medicina simultaneamente.

Luciana não pratica exercícios físicos. Vê-se impedida desta prática pelos problemas cardíacos, cujos esforços corporais demandados a cansam. Também não usa outros tratamentos caseiros, endossando a visão cosmológica do mundo regido por um ser superior capaz de castigar, recompensar e proteger. Neste sentido, evoca a proteção divina à preservação da própria saúde e de seus familiares. Como responsável pela saúde da família, relata atender às recomendaçooes médicas, alterando a forma de preparar e selecionar as comidas (redução do sal, introdução de legumes e verduras na alimentação, recomendados pela nutricionista), em parte facilitadas pela presença da mesma doença no grupo doméstico.

Essas mudanças não acontecem sem conflitos e tensões com o marido e os filhos, que demandam observar seus gostos pessoais e as tradições alimentares do grupo social em que foram socializados. Luciana gerencia com flexibilidade as restrições alimentares recomendadas, burlando-as para favorecer o próprio gosto e das demais pessoas do grupo doméstico, preservando também as tradiçôes alimentares aprendidas e as formas de lidar com o processo saúde, doença e os cuidados com o corpo, a alimentação e a saúde.

Refere preparar "comidas fortes", significando as que são capazes de saciar a fome, de fornecer a sensação de saciedade por tempo prolongado, de proporcionar maior energia ao corpo para trabalhar e as mais nutritivas pelo fato de possuírem "vitaminas", segundo o senso comum. Costuma preparar macarronada farta de molho de tomate e usar pimenta, que acredita elevar "a pressão". Não dispensa consumir torresmo, muito apreciado por todos e consumido parcimoniosamente (pelo menos uma vez ao mês) embora não desconheça as recomendações médicas e nutricionais de restringir o consumo de comidas gordurosas, como forma não medicamentosa de controlar a hipertensão arterial.

"Comer bem", ou seja, ingerir quantidade abundante de comidas, consideradas "fortes" e saborosas, segundo as escolhas e os gostos alimentares valorizados pelo grupo social, opõe-se ao "comer mal" nas representações das classes trabalhadoras. Isto significa dispor de pequenas quantidades de alimentos 
e da ausência no prato dos alimentos "fortes" (as carnes e alimentos gordurosos, principalmente). "Comer mal" reporta-se ainda às restriçôes alimentares, associadas simbolicamente à penúria, privação e miséria, dispensando também os alimentos que satisfazem o gosto, os sabores e as escolhas alimentares capazes de preservarem a identidade de pertencer a um grupo social (CANESQUI, 2005). Razões como esta conduzem à compreensão de uma das dificuldades de homens e mulheres das classes trabalhadoras de seguir as recomendações dietéticas restritivas.

Se as normas dietéticas de tratamento não medicamentoso da hipertensão arterial prescrevem reduzir o sal, o consumo de alimentos com gorduras saturadas e das bebidas alcoólicas, as recomendações de substituição por outros itens alimentares aspiram reorientar o comportamento alimentar, implicando sempre a resocialização do gosto e das escolhas alimentares cultivados ao longo das vidas e do processo de socialização dos sujeitos na família. Se, de um lado, a atribuição de "falta de educação dos pacientes serve à extensão da rede biomédica e a seus interesses no controle dos riscos e das doenças” (TESSER, 2010, p. 68), de outro, Boltanski (1979, p. 69) lembra que:

[...] o efeito de legitimidade do conhecimento biomédico não tem um peso suficiente para impedir que os agentes sociais mantenham um discurso qualquer sobre a doença, ou, pelo menos [...] reconstruir um discurso com materiais fragmentados e heteróclitos, palavras mal entendidas, frases desconexas, arrancadas do discurso médico.

A experiência de Luciana com a doença é vivida de forma destrutiva, correspondendo ao que se dá com o doente:

[...] a partir da interrupção da atividade provocada pela mesma, que se acompanha tanto pela destruição dos laços com os outros como as perdas diversas em suas capacidades e em seus papéis ele não consegue visualizar nenhuma possibilidade de reconstruir sua identidade, dependente inteiramente da integração social. (ADAM, HERZLICH, 2001, p. 78).

A condição de adoecimento por certas enfermidades de longa duração afeta profundamente a identidade da pessoa, impedindo reconstruí-la de forma positiva. Apesar dos sofrimentos morais e físicos que acompanham esta experiência e a própria vida de Luciana, agravados pelo fato de ela não se julgar inteiramente atendida em suas demandas e queixas pelos médicos e serviços de saúde, ela também se julga bem atendida e cuidada por eles. Condensa este cuidado e a confiança com a frase: "Para mim valeu. Está bom!”. 
Para concluir, observa-se que a "pressão alta" figura, nas representaçōes do grupo investigado, entre aquelas enfermidades que permitem conduzir normalmente a vida. Luciana não interpreta os acontecimentos físicos de maneira isolada e abstraída dos contextos, acontecimentos e circunstâncias da vida pessoal e social, como faz a biomedicina, mas conjuga a experiência com a enfermidade, com o corpo, saúde e doença e as afliçōes de vida aos sofrimentos morais, perturbadores de sua existência física, social, afetiva e relacional - ou seja, à pessoa concebida como totalidade.

\section{Referências}

ADAM, P.; HERZLICH, C. Sociologia da doença. Bauru: EDUSC, 2001.

ADAMSON, C. Existencial and clinical uncertainly in the medical encounter. Sociol. Health Illn., v.19, n.2, p.133-160,1997.

ALVES, P.C.B.; SOUZA, I.M. Escolha e avaliação de tratamento para problemas de saúde: considerações sobre o itinerário terapêutico. In: RABELO, M.C.; ALVES, P.C.B.; SOUZA, I.M. (Orgs.). Experiência de doença e narrativa. Rio de Janeiro: Fiocruz, 1999. p. 125-138.

BARSAGLINI, R.A. As representaçôes sociais e a experiência com o diabetes: um enfoque socioantropológico. Rio de Janeiro: Fiocruz, 2011.

BOLTANSKI, L. As classes sociais e o corpo. Rio de Janeiro: Graal, 1979.

BRASIL. Ministério da Saúde. Avaliação da implementação do PSF em dez grandes centros urbanos: síntese dos resultados. Brasília: Ministério da Saúde, 2002b.

BRASIL. Ministério da Saúde. Avaliação na Atenção Básica em Saúde: caminhos da institucionalização. Brasília: Ministério da Saúde, 2005.

BRASIL. Ministério da Saúde. Hipertensão arterial sistêmica. (Normas e Manuais). Brasília: Ministério da Saúde, 2006.

BRASIL. Ministério da Saúde. O PSF: evolução e sua implementação no Brasil. Brasília: Ministério da Saúde, 2002a.

BURY, M. Chronic illness and biographic disruption. Sociol. Health Illn., v.4, n.2, p.167$182,1982$.

The Sociology of chronic illness: a review of research and prospects. Sociol. Health Illn., n.23, v.4, p.451-468, 1991.

CAMARGO JR., K.R. Estratégia da Saúde da Família: percalços de uma trajetória. Physis: Revista de Saúde Coletiva. Rio de Janeiro, v.18, n.1, p.9-11, 2008. 
CANESQUI, A.M. "Pressão alta": significados e narrativas. Relatório de Projeto de Pesquisa.

Departamento de Medicina Preventiva e Social. Faculdade de Ciências Médicas. Campinas: Universidade Estadual de Campinas, 2010.

Consumo e avaliação de serviços de saúde. In: SPÍNOLA, A.W. et al. (Orgs.). Pesquisa Social em Saúde. São Paulo: Cortez, 1992. p. 91-99.

. Hipertensão do ponto de vista dos adoecidos. In: (Org.). Olhares socioantropológicos sobre os adoecidos crônicos. São Paulo: Hucitec, 2007. p. 87-110.

. Mudanças e permanências da prática alimentar cotidiana de famílias trabalhadoras. In: CANESQUI, A.M.; GARCIA, R.W.D. (Orgs.). Antropologia e Nutrição: um diálogo possível. Rio de Janeiro: Fiocruz, 2005. p.167-210.

CARVALHO, F.R.; TELAROLLI, JR., R.; MACHADO, J.C.M. Uma investigação antropológica na terceira idade: concepções sobre a hipertensão arterial. Cad de Saúde Pública, n.14, v.3, p.617-21, 1998.

CHAMMÉ, S.J. Intervenção sanitária na saúde e doença: o avanço das discussões. In: CANESQUI, A.M. (Org.). Ciências sociais e saúde para o ensino médico. São Paulo: Hucitec, 2000, p.271-283.

CORBIN, J.; STRAUSS, A. Managing chronic illness at home: three lines of work. Qual. Sociology, v.8, n.3, p.224-247, 1985.

DUARTE, L.F.D. Da vida nervosa nas classes trabalhadoras urbanas. Rio de Janeiro: Zahar, 1986.

FIRMO, J.O.A.; COSTA-LIMA, M.F.; UCHOA, E. Projeto Bambuí. Maneiras de pensar e agir dos idosos hipertensos. Cad. Saúde Pública, v.20, n.4, p.1029-1040, 2004.

GOLDBAUM, M. et al. Utilização de serviços de saúde em áreas cobertas pelo programa de Saúde da Família (Qualis) no Município de São Paulo. Rev. Saúde Pública, n.39, v.1, p.90-99, 2005.

HERZLICH, C.; PIERRET, J. Malades d'hier, maladies d'aujourd'hui. Paris: Payot, 1984. HEUERTIN-ROBERTS, S:, RUSSIN, E.E. Folk models of hypertension among black women: problems in illness managing. In: ROBERTSON, J. (Ed.). Anthropology and primary care. Amsterdan: Elsevier, 1983. p.151-173.

KLEINMAN, A.; SEEMAN, D. Personal experience of illness. In: ALBERTCH, G.L.; FITZPATRIC, R.; SCRIMSHAW, S.C. (Eds.). The Handbook of Social Studies in Health and Medicine. London: Sage, 2000. p. 230-242.

LÉVI-STRAUSS, C. O pensamento selvagem. Rio de Janeiro: Cia Editora Nacional, 1970. LOYOLA, M.A. Médicos e curandeiros: conflito social e saúde. São Paulo: Difel, 1984. 
MACIEL, C.L.C. Hipertensão essencial: emoção, doença e cultura. Dissertação (Mestrado em Antropologia) - Centro de Filosofia e Ciências Humanas, Universidade Federal de Pernambuco, Recife, 1988.

MASSÉ, R. Culture et santé publique. Les contributions de l'anthropologie à la prevention et à la promotion de la santé. Montreal: Gaétan Morin, 1985. p. 330-348.

PIERRET, J. The illness experience: state of knowledge and perspectives for research. Sociol. Health Illn., 25 Aniversary Issue, p. 4-22, 2003.

. Des conceptions de la maladie à l'analyse de la realité social. Sc.Soc et Santé, v.6, n.3, p.167-170, 1988.

- Entre santé et experience de la maladie. Disponível em www.youscribe.com/ catalogue rapports-et-theses/saviores/science. Acesso em: 6 set 2013.

An analysis over time (1990-2000) of the experience of living with HIV. Soc. Sc.Medic., n. 65, v.8, p.1595-605, 2007.

QUEIROZ, M.I. Relatos orais: do “indizível” ao “dizível”. Cienc. Cult., v.39, n.3, p.272286, 1987.

RABELO, M.C.M.; ALVES, P.C.B.; SOUZA, I.M. Signos, significados e práticas relativos à doença mental. In: . (Orgs.). Experiência de doença e narrativa. Rio de Janeiro: Fiocruz, 1999. p.43-73.

RADLEY, A.; GREEN, R. Styles of adjustment to coronary graft surgery. Soc. Sc. Medicine, v.20, p.179-207, 1987.

STAKE, R.S. Case Studies. In: DENZIN, N.K.; YVONNA, S. (Orgs.). The handbook of qualitative research. 2.Ed. London: Sage, 2000. p. 435-454.

STRAUSS, A; GLASER, B. (Eds.) Chronic illness and quality of life. St. Louis: The C.V. Mosby Company, 1975.

TESSER, C.D. Medicalização social: uma leitura a partir de Illich e Fleck. In:

(Org.). Medicalização social e atenção à saúde no SUS. São Paulo: Hucitec, 2010. p.52-73.

TRAD, L.B. et al. Itinerários terapêuticos face à hipertensão arterial em famílias de classe popular. Cad. Saúde Pública, n.26, v.2, p.797-806, 2010.

VIEIRA, V.A. Narrativas sobre hipertensão arterial e diabetes mellitus e os sentidos nelas produzidos por pessoas atendidas em grupos de aconselhamento. Tese (Doutorado em Saúde Pública) - Instituto Fernandes Figueira, Fundação Oswaldo Cruz, Rio de Janeiro, 2004.

\section{Notas}

${ }^{1}$ Pierret compreende a relação não causal e determinista, mas circular e recíproca da experiência singular da enfermidade com a dinâmica da estrutura e organização da sociedade dadas pelas condições políticas, econômicas, ideológicas e sociais, mutáveis nas diferentes épocas e contextos históricos. Estes elementos coletivos e macro-estruturais interferem tanto na organização do cuidado médico, 
no saber e instituições médicas e nas visões de mundo coletivas, quanto nas diferenças de gênero e origem social dos adoecidos (dadas em termos de condiçôes ou dos modos de vida, dos valores e representações individuais e coletivas sobre corpo, saúde e doença e às formas concretas de convívio e de ajustamento às enfermidades integrantes da experiência com a enfermidade.

Critica as investigações anglo-saxônicas sincrônicas, formais e atemporais da experiência da enfermidade que não a inscrevem na dinâmica social, mutável no tempo e inscrita nas referências sociais, na história social, nas transformaçôes institucionais, do saber e práticas médicas de uma época, sempre permeadas da interferência das condições políticas, econômicas, ideológicas e sociais (PIERRET, 1988). Outras referências à experiência com a enfermidade (HERZLICH; PIERRET, 1984), extraídas da produção acadêmica francesa, ultrapassam a dimensão individual à medida que cada sociedade possui suas doenças e seus doentes, sendo a doença e a experiência socialmente construídas e historicamente situadas. Sua análise demanda articular a história social com a sociologia, o recurso a diferentes fontes de informações e o acompanhamento longitudinal e comparativo das doenças e das diferentes categorias sociais de doentes na sociedade. As doenças também encarnam simbolicamente a relação do indivíduo com a sociedade, abandonando, portanto, sua materialidade nos corpos, posta pela biomedicina.

Para Pierret (2012), é a sociedade que está na origem das categorias sociais fundadas nas desigualdades sociais básicas expressas nos lugares ocupados pelos grupos e indivíduos na organização social, nas condições de vida, nas diferenças em relação à educação ou aos tratamentos médicos, assim como em relação aos valores de referência. Trata-se de incluir a experiência nestes condicionantes de natureza social, médico-institucionais e valorativos.

Estudo sobre a experiência de enfermos de Aids (PIERRET, 2007) aborda a evolução da construção social e médica da doença no contexto histórico da sociedade francesa no período 1990 a 2000; a gênese da mobilização midiática e associativa dos enfermos; as consequências dos modos de vida e dos recursos mobilizados pelos adoecidos; as representaçôes sociais da condução da vida normal com a enfermidade, ao lado das representaçóes flutuantes vigentes no contexto concreto da sociedade, do estado do conhecimento médico e da experiência concreta de convívio com a enfermidade, incluindo também os diferentes modos de ajustamento à condição de enfermo.

${ }^{2}$ As investigações anglo-saxônicas sobre as estratégias de ajustamentos às enfermidades crônicas em geral se valem do conceito de coping, que se refere ao processo de aprendizagem individual de convívio ou tolerância com os efeitos das enfermidades, que segundo Bury (1991), ancora-se nos fatores psicológicos e relacionais. Estilo é outro conceito usado e entendido como a forma como as pessoas manejam no presente a enfermidade, os regimes e os tratamentos (BURY, 1982). Radley \& Green (1985), influenciados pelo trabalho de Pierre Bordieu sobre os estilos de classe que acompanham os comportamentos corporais ou do self, referem-se ao estilo aos significados e às práticas sociais das diferentes classes sociais afetando as formas de manejar as enfermidades. Normalização, no sentido biomédico, associa-se à adaptação, enquanto para os sociólogos o conceito reporta-se a um conjunto de ações e de interpretações que possibilitam construir uma "nova atitude natural" (ADAM; HERZLICH, 2001, p. 125).

${ }^{3} \mathrm{O}$ estudo original do qual se extraiu o caso analisado foi aprovado pelo Comitê de Ética da Faculdade de Ciências Médicas da Universidade Estadual de Campinas. Foi também financiado pelo CNPq (processo no 471418-2007-2), ao qual a autora agradece pelo apoio recebido. 


\section{Abstract}

\section{A case study about the experience with "high blood pressure"}

This paper discusses the experience with "high blood pressure" and associated diseases posited as physical and moral sufferings in the whole person who lives, works and reflects amid life circumstances that affect him. This is a case study of a qualitative research on narrative and meaning of "high pressure", made with 17 men and 20 women diagnosed for over a year with hypertension, users of a Family Health Unit of an inland city in São Paulo state. Two reasons guided the case selection: being included among the seven interviewees who mentioned having discovered hypertension at the time spent by the heart attack or stroke, and being female. Data were obtained through semi-structured interviews about perceived health conditions, discovery of the disease, explanation of its genesis, therapeutic itineraries, social support received; relations with health services and other curing agents and management of medical prescriptions. This study displays the interconnections and unique personal experience of illness with the broader sociocultural contexts, moral values, social relations and social representations of the body, health, illness and care shared with the working class.

> Key words: illness experience; arterial hypertension; social sciences and health; qualitative research on health. 